\title{
High serum ferritin is associated with worse outcome of patients with decompensated cirrhosis
}

\author{
Theodora Oikonomou, loannis Goulis, Stergios Soulaidopoulos, Areti Karasmani, Petros Doumtsis, \\ Konstantina Tsioni, Eudokia Mandala, Evangelos Akriviadis, Evangelos Cholongitas
}

Hippokration General Hospital, Medical School Aristotle University of Thessaloniki, Greece

\section{Abstract}

\section{Introduction}

Decompensated cirrhosis is characterized by striking and life-threatening complications, such as variceal hemorrhage

$4^{\text {th }}$ Department of Internal Medicine, Hippokration General Hospital, Medical School Aristotle University of Thessaloniki, Greece

\section{Conflict of Interest: None}

Correspondence to: Evangelos Cholongitas, Ass. Professor of Internal Medicine, $4^{\text {th }}$ Department of Internal Medicine, Medical School of Aristotle University, Hippokration General Hospital of Thessaloniki, 49, Konstantinoupoleos Street, 54642 Thessaloniki, Greece,

Tel.: +30 2310 892110, Fax: +30 2310992940 ,

e-mail: cholongitas@yahoo.gr

Received 11 August 2016; accepted 08 November 2016; published online 08 December 2016

DOI: https://doi.org/10.20524/aog.2016.0112 and spontaneous bacterial peritonitis (SBP). Bacterial infections are common in patients with decompensated cirrhosis due to enhanced bacteria translocation from the intestine and altered immune response, the cirrhosis associated systemic inflammatory response [1]. Once decompensation has occurred, mortality without liver transplantation (LT) is as high as $85 \%$ over 5 years [2]. However, the large number of prognostic studies of cirrhosis performed during the last decades indicates uncertainty and dissatisfaction with the available prognostic models [3]. In general, there is need to use easily derived markers that provide accurate prediction for decompensated cirrhosis patients. Serum ferritin is universally available biochemical parameter, elevated in several clinical conditions including patients with both acute and chronic liver diseases [4]. Ferritin synthesis is induced by macrophages and hepatocytes and raised levels can be seen either in iron overload conditions or in several pathologies, inflammation, infection and liver diseases [5-7]. In response to high iron and 
inflammation, liver also synthesizes and secretes hepcidin, an iron-regulating hormone $[8,9]$, which affects iron metabolism and ferritin synthesis. Besides, it is known that hepcidin levels correlate negatively with hepatic function $[10,11]$.

Hence, the hyperferritinemia seen in decompensated cirrhosis could be attributed either to the endotoxinemia of cirrhosis itself, which induces higher ferritin synthesis, or to the deficient hepcidin production by the cirrhotic liver, which leads to elevated iron absorption [11]. In fact, recent studies confirmed the above observation: Walker et al showed that serum ferritin could be used as an independent predictor of mortality in cirrhotic patients awaiting LT and high levels were associated with a higher frequency of liver-related complications [12], while Maiwall et al found that ferritin was an independent prognostic biomarker for early liver-related death, at 15 days and at 1 month, in hospitalized patients with decompensated cirrhosis [13].

Furthermore, literature data suggest other noninvasive parameters, such as red blood cell distribution width (RDW) and mean platelet volume (MPV), have predictive role in patients with chronic liver diseases [14]. There are only few studies assessing the correlation of RDW and MPV with the severity of liver cirrhosis.Huang et al showed that RDW reflects the severity of hepatitis B virus (HBV)-related cirrhosis [15]. Another study defined RDW and MPV as independent predicting factors in liver fibrosis [14], but Giannini et al concluded that MPV has no association with severity of disease and prognosis in patients with established cirrhosis [16].

We hence conducted this study to investigate, for the first time in the same cohort, the role of serum ferritin and RDW/ MPV in the outcome (survival, death, or LT) of patients with stable decompensated cirrhosis.

\section{Patients and methods}

Consecutive adult patients with stable decompensated cirrhosis admitted to our department between September 2010 until February 2016 with complete data including serum ferritin levels as well as RDW and MPV evaluation were included. All patients had been admitted to our department for LT waiting list registration, and their outcome (alive, death, or LT) was evaluated after a follow up of at least 6 months (unless death or LT occurred earlier). In our study, decompensated cirrhosis was defined as a history of ascites, variceal bleeding, encephalopathy or non-obstructive jaundice in patients with known cirrhosis. The presence of ascites was detected by clinical examination and imaging techniques (ultrasound or computed tomography). We evaluated our patients for the presence of infection based on clinical, laboratory [white blood count, C-reactive protein (CRP), procalcitonin, ascitic fluid paracentesis, urine examination] and imaging methods (chest x-ray, upper abdominal ultrasound). We excluded patients with infection (e.g. SBP) as well as an episode of active bleeding or encephalopathy at baseline and for 1 month prior to their admission.
The following demographic and clinical variables were recorded for each patient on admission: age; sex; cause and duration of liver disease; previous complications of cirrhosis (i.e. variceal bleeding, encephalopathy or SBP); medication administered for the liver disease (duration and dosage); and vital signs (blood pressure, pulse rate). On admission to our department we also evaluated the following laboratory variables: hemoglobin, mean corpuscular volume (MCV), platelets (PLT), albumin, protein, bilirubin (total and direct), clotting profile [prothrombin time (PT), activated partial thromboplastin time (aPTT), international normalized ratio (INR)], creatinine, cystatin-C, electrolytes [e.g. sodium $(\mathrm{Na})$ and potassium $(\mathrm{K})$ ], CRP, procalcitonin, lipidemic profile [cholesterol, triglycerides, high-density lipoprotein (HDL), low-density lipoprotein] creatine phosphokinase $(\mathrm{CPK})$, aminotransferases (aspartate and alanine), alkaline phosphatase, $\gamma$-glutamyl transpeptidase and lactate dehydrogenase. Furthermore, serum ferritin, RDW, and MPV were recorded in each patient. Child-Turcotte-Pugh (CTP) [17] and model for end-stage liver disease (MELD) [18] scores were calculated for all patients to evaluate the severity of liver disease.

In addition, we extended our patients' evaluation by obtaining a 24-h urine collection for calculation of urine sodium (24UNa) and random urine samples before or usually after completion of 24-h collection for measurement of "spot" urine $\mathrm{Na}$ and $\mathrm{K}$ concentrations. So, we calculated their ratio ( $\mathrm{UNa} / \mathrm{K}$ ratio), which has been associated with the presence of low natriuresis (i.e. $24 \mathrm{Una}<78 \mathrm{mmoL} /$ day) and outcome [19]. Finally, we assessed renal function ("true" glomerular filtration rate, GFR) using ${ }^{51}$ Chromium-EDTA ( ${ }^{51} \mathrm{Chr}$-EDTA) [20] along with estimated GFR (eGFR) using the creatinine-based 4 variables modification of the diet in renal disease (MDRD) formula [21] and the chronic kidney disease-epidemiology (CKD-EPI) creatinine-based formula [22]. The study protocol was approved by our Institutional Review Board and conformed to the ethical guidelines of the 1975 Declaration of Helsinki.

\section{Statistical analysis}

All data were analyzed using the statistical package SPSS (version 22.0 IBM Corp: Armonk NY USA) and MedCalc for Windows (MedCalc Software, Mariakerke, Belgium). Primarily, we evaluated the outcome of our patients (survival or death and LT) and its correlation with serum ferritin. The $\chi^{2}$ test was used for comparing qualitative variables and Student's $t$-test and Mann-Whitney $U$ test for comparing quantitative continuous variables. Quantitative variables which were normally distributed were expressed as mean values \pm one standard deviation (SD) and those non-normally distributed were expressed as median values (range). Multivariate Cox regression analysis was performed using backward selection of variables, starting with all variables with $\mathrm{P}<0.1$ in univariate analysis to find the independent factors significantly associated with the outcome. The discriminative ability of ferritin to predict the outcome of patients with decompensated cirrhosis was evaluated by using the area under a receiver operating characteristic curve (AUC). This has the true-positive and 
false-positive rates on the vertical and horizontal axes, respectively. As the AUC approaches 1.0, the model approaches $100 \%$ sensitivity and specificity [23]. At the best cut-off point (in which the sum of sensitivity plus specificity is maximal), sensitivity, specificity, positive (PPV) and negative (NPV) predictive values were calculated. Patients' survival according to the best cut-off point of ferritin was calculated using KaplanMeier analysis and compared with the log-rank sum test. A P value $\leq 0.05$ was considered statistically significant.

\section{Results}

In the present study, we included 192 consecutive patients with stable decompensated cirrhosis. Their baseline characteristics of the cohort are shown in Table 1. On admission 31 (16\%) had hepatocellular carcinoma (HCC) (all within Milan criteria), 142 (74\%) were male and mean age was $54.2 \pm 12$ years. Viral hepatitis was the cause of cirrhosis in 93 (48\%) patients. On admission, the median (range) value of ferritin was 161 (5-3397) $\mathrm{ng} / \mathrm{mL}$ and the mean values of RDW and MPV were $16.8 \pm 5 \%$ and $8.9 \pm 4 \mathrm{fL}$, respectively. The mean CTP and MELD scores were $8.3 \pm 1.8$ and $15 \pm 6$, respectively. All patients had a previous history of ascites and/or were under diuretics (furosemide: $20-80 \mathrm{mg} /$ day and spironolactone: 50-200 mg/day). Forty three (22.4\%), 64 (33.4\%) and $27(14.1 \%)$ of the patients had previous history of variceal bleeding, hepatic encephalopathy and SBP, respectively, prior to their admission. The median value of "true" GFR was 75 (range: $16-131$ ) $\mathrm{mL} / \mathrm{min} / 1.73 \mathrm{~m}^{2}$.

\section{Characteristics of patients with or without normal serum ferritin levels (Table 2)}

According to the reference range of our laboratory (lower and upper normal values for men: 22 and $322 \mathrm{ng} / \mathrm{mL}$; for women: 22 and $291 \mathrm{ng} / \mathrm{mL}$, respectively), we divided our cohort in two groups: those with ferritin levels above the upper limit of normal ("abnormal ferritin", group 1, n=60 or $31.2 \%$ ) and those with low or normal ferritin levels ("normal ferritin", group 2, n=132 or $68.8 \%$ ). Group 1, compared to group 2 patients, had less frequently a previous history of variceal bleeding [11.6\% (7/60) vs. $27.3 \%(36 / 132), \mathrm{P}=0.016)]$, but more frequently hepatic encephalopathy [45\% (27/60) vs. $28 \%(37 / 132), \mathrm{P}=0.016)]$ and SBP $[23.3 \%(14 / 60)$ vs. $9.8 \%$ (13/132), $\mathrm{P}=0.012)]$. No difference was found regarding the presence of HCC [15\% (9/60) vs. $16.7 \%(22 / 132), \mathrm{P}=0.77)]$. In addition, group 1 compared to group 2 patients had significantly lower hemoglobin ( $10.8 \pm 3$ vs. $11.5 \pm 4 \mathrm{~g} / \mathrm{dL}, \mathrm{P}=0.002$ ), but higher levels of serum creatinine (mean \pm SD: $1.2 \pm 0.5$ vs. $1.03 \pm 0.4 \mathrm{mg} / \mathrm{dL}, \mathrm{P}=0.04)$, total bilirubin [median (range): 3.1 (0.7-35) vs. $1.9(0.3-34.7) \mathrm{mg} / \mathrm{dL}, \mathrm{P}=0.019]$, prothrombin time (mean \pm SD: $18.5 \pm 8.1$ vs. $15.6 \pm 3.5 \mathrm{sec}, \mathrm{P}=0.021$ ), aPTT (mean \pm SD: $47.2 \pm 19.3$ vs. $40.3 \pm 8.8 \mathrm{sec}, \mathrm{P}=0.02$ ) and INR (mean \pm SD: $1.7 \pm 0.6$ vs. $1.3 \pm 0.3, \mathrm{P}=0.008$ ). Finally, group 1
Table 1 Baseline clinical and laboratory characteristics of 192 patients with stable decompensated cirrhosis

\begin{tabular}{|c|c|}
\hline Variable & Patients, $\mathrm{n}=192$ \\
\hline Age (mean $\pm S D$, years) & $54.2 \pm 12$ \\
\hline Sex, male $n,(\%)$ & $142(74)$ \\
\hline $\begin{array}{l}\text { Cause of cirrhosis n, (\%) } \\
\text { Viral hepatitis } \\
\text { Alcohol } \\
\text { NASH/Cryptogenic } \\
\text { Others }\end{array}$ & $\begin{array}{l}93(48) \\
48(25) \\
25(13) \\
26(14)\end{array}$ \\
\hline $\begin{array}{l}\text { Grade of ascites, } \mathrm{n},(\%) \\
\text { Grade } 0-2 \\
\text { Grade } 3 \\
\text { Grade } 4 \text { (refractory ascites) }\end{array}$ & $\begin{array}{l}150(78.3) \\
29(15) \\
13(6.7)\end{array}$ \\
\hline HRS type II, n, (\%) & $18(9.4)$ \\
\hline $\begin{array}{l}\text { CKD-EPI-estimated GFR (median, range), } \\
\mathrm{mL} / \mathrm{min} \\
\mathrm{MDRD} \text {-estimated GFR (median, range), } \\
\mathrm{mL} / \mathrm{min}\end{array}$ & $\begin{array}{l}78 \text { (range: } 25-141 \text { ) } \\
82 \text { (range: } 30-159)\end{array}$ \\
\hline $\begin{array}{l}\text { "True" GFR by }{ }^{51} \text { Chromium-EDTA } \\
\text { (median, range), } \mathrm{mL} / \mathrm{min}\end{array}$ & 75 (range: $16-131$ ) \\
\hline Ferritin (median, range), ng/mL & $161(5-3397)$ \\
\hline RDW (mean \pm SD, \%) & $16.8 \pm 5$ \\
\hline $\mathrm{MPV}($ mean $\pm \mathrm{SD}, \mathrm{fL})$ & $8.9 \pm 4$ \\
\hline Child-Turcotte-Pugh score (mean \pm SD) & $8.3 \pm 1.8$ \\
\hline MELD score, $($ mean \pm SD) & $15 \pm 6$ \\
\hline $\begin{array}{l}\text { HRS, hepatorenal syndrome; } C K D-E P I \text {, chronic } \\
M D R D, \text { modification of the diet in renal disease; } \\
\text { teatohepatitis; GFR, glomerular filtration rate; } \\
\text { width; } M P V \text {, mean platelet volume; SD, standard } \\
\text { end-stage liver disease }\end{array}$ & $\begin{array}{l}\text { disease-epidemiology; } \\
\text {, non-alcoholic } \\
\text { red cell distribution } \\
\text { tion; MELD, model for }\end{array}$ \\
\hline
\end{tabular}

compared to group 2 patients had significantly higher CTP score $(8.8 \pm 2$ vs. $7.8 \pm 2, \mathrm{P}=0.022)$ and MELD score $(16.7 \pm 6$ vs. $12.9 \pm 5, \mathrm{P}=0.013)$.

No difference was found between the two groups regarding: CRP ( $7 \pm 3$ vs. $5 \pm 2 \mathrm{mg} / \mathrm{L}, \mathrm{P}=0.81$ ), "true" GFR ( $70 \pm 30$ vs. $77 \pm 22 \mathrm{~mL} / \mathrm{min}, \mathrm{P}=0.13$ ) as well as eGFRs using the MDRD and CKD-EPI formulas. The etiology of underlying liver disease was not significantly associated with serum ferritin levels (e.g. median values for alcoholic vs. non-alcoholic: 175 vs. $151 \mathrm{ng} / \mathrm{mL}, \mathrm{P}=0.33$ ).

\section{Serum ferritin and outcome}

During the follow-up period [median 12 (1-64) months], 130 patients died or underwent LT and 62 remained alive. All patients who died had liver-related deaths. The patients who died or underwent LT compared to alive patients had higher levels of ferritin [204 (9-3397) vs. 109 (5-1189) ng/mL, $\mathrm{P}=0.019]$ and they had more frequently ferritin above the upper limit of normal $[47 / 130$ or $36 \%$ vs. $13 / 62$ or $21 \%, \mathrm{P}=0.034$, respectively]. As it was expected, MELD and CTP scores were significantly associated with the outcome (Table 3 ). In 
Table 2 Univariate analysis to evaluate the factors associated with the presence of normal or abnormal levels of serum ferritin in 192 patients with stable decompensated cirrhosis

\begin{tabular}{|c|c|c|c|}
\hline Variable & $\begin{array}{l}\text { Patients with } \\
\text { ferritin above limit } \\
\text { of normal }(n=60)\end{array}$ & $\begin{array}{l}\text { Patients with low or } \\
\text { normal ferritin }(n=132)\end{array}$ & $P$ value \\
\hline \multicolumn{4}{|l|}{ History of complications $\mathrm{n},(\%)$} \\
\hline Encephalopathy & $27(45)$ & $37(28)$ & 0.016 \\
\hline GI bleeding & $7(11.6)$ & $36(27.3)$ & 0.016 \\
\hline Spontaneous bacterial peritonitis & $14(23.3)$ & $13(9.8)$ & 0.012 \\
\hline \multicolumn{4}{|l|}{ Etiology of cirrhosis, n (\%) } \\
\hline Alcohol & $17(28)$ & $33(25)$ & 0.71 \\
\hline Systolic arterial blood pressure $($ mean $\pm \mathrm{SD}, \mathrm{mmHg})$ & $107 \pm 26$ & $112 \pm 24$ & 0.35 \\
\hline Hemoglobin, $($ mean $\pm S D, g / d L)$ & $10.8 \pm 3$ & $11.5 \pm 4$ & 0.002 \\
\hline Mean corpuscular volume (mean \pm SD, fL) & $77 \pm 13$ & $75 \pm 17$ & 0.22 \\
\hline Serum iron $($ mean $\pm S D, \mu g / d L)$ & $85 \pm 29$ & $78 \pm 31$ & 0.15 \\
\hline Albumin $($ mean $\pm S D, g / d L)$ & $3.3 \pm 1.2$ & $3.2 \pm 0.6$ & 0.01 \\
\hline Bilirubin (median, range, mg/dL) & $3.1(0.7-35)$ & $1.9(0.3-34.7)$ & 0.019 \\
\hline $\mathrm{PT}(\mathrm{mean} \pm \mathrm{SD}, \mathrm{sec})$ & $18.5 \pm 8.1$ & $15.6 \pm 3.5$ & 0.021 \\
\hline aPTT (mean \pm SD, sec) & $47.2 \pm 19.3$ & $40.3 \pm 8.8$ & 0.02 \\
\hline $\operatorname{INR}($ mean \pm SD) & $1.7 \pm 0.6$ & $1.3 \pm 0.3$ & 0.008 \\
\hline Creatinine $($ mean $\pm \mathrm{SD}, \mathrm{mg} / \mathrm{dL})$ & $1.2 \pm 0.5$ & $1.03 \pm 0.4$ & 0.04 \\
\hline Cystatin-C (mean $\pm \mathrm{SD}, \mathrm{mg} / \mathrm{dL})$ & $1.9 \pm 0.7$ & $1.8 \pm 0.8$ & 0.61 \\
\hline “True" GFR (mean \pm SD, mL/min) & $70 \pm 30$ & $77 \pm 22$ & 0.13 \\
\hline Sodium $($ mean $\pm \mathrm{SD}, \mathrm{mmol} / \mathrm{L})$ & $129 \pm 24$ & $134 \pm 17$ & 0.13 \\
\hline $\mathrm{CRP}($ mean $\pm \mathrm{SD}, \mathrm{mg} / \mathrm{L})$ & $7 \pm 3$ & $5 \pm 2$ & 0.81 \\
\hline Procalcitonin $($ mean $\pm \mathrm{SD}, \mathrm{ng} / \mathrm{mL})$ & $0.8 \pm 0.2$ & $0.9 \pm 0.4$ & 0.95 \\
\hline Cholesterol (mean $\pm \mathrm{SD}, \mathrm{mg} / \mathrm{dL})$ & $130 \pm 61$ & $138 \pm 61$ & 0.42 \\
\hline High-density lipoprotein $(\mathrm{HDL})(\mathrm{mean} \pm \mathrm{SD}, \mathrm{mg} / \mathrm{dL})$ & $32 \pm 13$ & $37 \pm 14$ & 0.11 \\
\hline $\mathrm{CPK}($ mean $\pm \mathrm{SD}, \mathrm{IU} / \mathrm{L})$ & $72 \pm 28$ & $88 \pm 39$ & 0.21 \\
\hline Child-Turcotte-Pugh score (mean \pm SD) & $8.8 \pm 2$ & $7.8 \pm 2$ & 0.022 \\
\hline MELD score $($ mean \pm SD) & $16.7 \pm 6$ & $12.9 \pm 5$ & 0.013 \\
\hline
\end{tabular}

CPK, creatine phosphokinase; CRP, C-reactive protein (normal<5 mg/L); GI, gastrointestinal; MELD, model for end-stage liver disease; SD, standard deviation; GFR, glomerular filtration rate; PT, prothrombin time; aPTT, activated partial thromboplastin time; INR, international normalized ratio

addition, several factors were associated with mortality or LT in univariate analysis (Table 3) including bilirubin (HR 1.04, 95\%CI 1.005-1.07, $\mathrm{P}=0.024)$, PT (HR 1.03, 95\%CI 1.01-1.07, $\mathrm{P}=0.004)$, aPTT (HR 1.02, 95\%CI 1.01-1.03, $\mathrm{P}<0.001)$, INR (HR 1.63, 95\%CI 1.24-2.16, $\mathrm{P}<0.001$ ), serum creatinine (HR $1.22,95 \%$ CI 1.02-2.54, $\mathrm{P}=0.05$ ), "true" GFR (HR 0.97, 95\%CI 0.95-0.99, $\mathrm{P}=0.011$ ), ferritin (HR 1.001, 95\%CI 1.0-1.001, $\mathrm{P}<0.001$ ), cholesterol (HR 0.99, 95\%CI 0.98-1.0, $\mathrm{P}=0.03$ ) and HDL (HR 0.98, 95\%CI 0.97-0.99, $\mathrm{P}=0.01$ ). However, RDW and MPV were not associated with the outcome (Table 3) irrespectively of the cause of the underlying disease (e.g. in alcohol and non-alcoholic liver disease). In multivariate Cox regression analysis, only "true" GFR (HR 0.96, 95\%CI 0.92$0.99, \mathrm{P}=0.035)$ and ferritin (HR 1.001, 95\%CI 1.00-1.002, $\mathrm{P}=0.005$ ) were independent factors of outcome (Table 4) and this was true in either genders, or when only death was considered (i.e. excluding the patients who underwent LT)
[HR for ferritin 1.001, 95\%CI 1.00-1.001, P<0.001]. Based on the area under the ROC curve (Fig. 1), ferritin had relatively low discriminative ability for the outcome (death or LT) (AUC=0.61, 95\%CI 0.52-0.69). The best cut-off point for the outcome was ferritin $>55 \mathrm{ng} / \mathrm{mL}$ giving sensitivity, specificity, PPV and NPV 85.3\%, 44.2\%, 78\% кaı 79\%, respectively (Table 5) and according to the Kaplan-Meier, patients with ferritin $>55 \mathrm{ng} / \mathrm{mL}(\mathrm{n}=145)$ had worse outcome, compared to those with ferritin $\leq 55 \mathrm{ng} / \mathrm{mL}(\mathrm{n}=47)$ (log-rank $\mathrm{P}=0.001)$. The patients who died or underwent LT compared to those alive had more frequently ferritin $>55 \mathrm{ng} / \mathrm{mL}[113 / 130$ or $87 \%$ vs. $32 / 62$ or $51.5 \%, \mathrm{P}<0.001]$. Finally, the patients with above the upper limit of normal ferritin $(n=60)$ had significantly worse outcome, compared to those with low or within normal ferritin $(n=132)$ (log-rank $P=0.019)$ (Fig. 2) and remained significant when the patients with HCC were excluded (logrank $\mathrm{P}=0.004)$. 
Table 3 Clinical and laboratory characteristics of 192 patients with stable decompensated cirrhosis associated with the outcome (univariate analysis)

\begin{tabular}{|c|c|c|c|c|}
\hline \multirow[t]{2}{*}{ Variable } & \multirow[t]{2}{*}{ Hazard ratio } & \multirow[t]{2}{*}{$P$ value } & \multicolumn{2}{|c|}{ 95\% Confidence interval } \\
\hline & & & Lower & Upper \\
\hline \multicolumn{5}{|l|}{ History of complications n, (\%) } \\
\hline Encephalopathy & 1.11 & 0.62 & 0.72 & 1.71 \\
\hline GI bleeding & 1.08 & 0.77 & 0.67 & 1.69 \\
\hline Spontaneous bacterial peritonitis & 1.20 & 0.56 & 0.67 & 2.15 \\
\hline Systolic arterial blood pressure $($ mean $\pm \mathrm{SD}, \mathrm{mmHg})$ & 1.0 & 0.99 & 0.98 & 1.008 \\
\hline Albumin $($ mean $\pm \mathrm{SD}, \mathrm{g} / \mathrm{dL})$ & 0.81 & 0.19 & 0.60 & 1.10 \\
\hline Bilirubin (median, range, $\mathrm{mg} / \mathrm{dL}$ ) & 1.04 & 0.024 & 1.005 & 1.07 \\
\hline $\mathrm{PT}(\mathrm{mean} \pm \mathrm{SD}, \mathrm{sec})$ & 1.03 & 0.004 & 1.01 & 1.07 \\
\hline aPTT (mean \pm SD, sec) & 1.02 & $<0.001$ & 1.01 & 1.03 \\
\hline INR $($ mean \pm SD) & 1.63 & $<0.001$ & 1.24 & 2.16 \\
\hline Creatinine $($ mean $\pm \mathrm{SD}, \mathrm{mg} / \mathrm{dL})$ & 1.22 & 0.05 & 1.02 & 2.54 \\
\hline Cystatin-C (mean $\pm \mathrm{SD}, \mathrm{mg} / \mathrm{dL})$ & 1.14 & 0.55 & 0.72 & 1.81 \\
\hline Glomerular filtration rate, $($ mean $\pm \mathrm{SD}, \mathrm{mL} / \mathrm{min})$ & 0.97 & 0.011 & 0.95 & 0.99 \\
\hline Sodium $($ mean $\pm \mathrm{SD}, \mathrm{mmol} / \mathrm{L})$ & 0.98 & 0.58 & 0.96 & 1.01 \\
\hline Ferritin $($ mean $\pm S D, n g / m L)$ & 1.001 & $<0.001$ & 1.00 & 1.001 \\
\hline $\mathrm{RDW}($ mean $\pm \mathrm{SD}, \%)$ & 1.02 & 0.53 & 0.96 & 1.09 \\
\hline $\mathrm{MPV}($ mean $\pm \mathrm{SD}, \mathrm{fL})$ & 0.95 & 0.41 & 0.84 & 1.08 \\
\hline Cholesterol (mean $\pm \mathrm{SD}, \mathrm{mg} / \mathrm{dL})$ & 0.99 & 0.03 & 0.98 & 1.00 \\
\hline High-density lipoprotein (mean \pm SD, mg/dL) & 0.98 & 0.01 & 0.97 & 0.99 \\
\hline $24 \mathrm{UNa}(\mathrm{mean} \pm \mathrm{SD}, \mathrm{mmoL} /$ day $)$ & 0.99 & 0.73 & 0.98 & 1.003 \\
\hline $\mathrm{UNa} / \mathrm{K}$ ratio (median, range) & 0.96 & 0.46 & 0.86 & 1.07 \\
\hline Child-Turcotte-Pugh score & 1.30 & 0.005 & 1.04 & 1.47 \\
\hline MELD score & 1.08 & 0.003 & 1.01 & 1.12 \\
\hline
\end{tabular}

$R D W$, red blood cell distribution width; MPV, mean platelet volume; $U N a / K$, urine sodium to potassium ratio; $24 U N a$, 24h excretion of sodium in urine; $C P K$, creatine phosphokinase; GI, gastrointestinal; MELD, model for end-stage liver disease; SD, standard deviation; PT, prothrombin time; aPTT, activated partial thromboplastin time; INR, international normalized ratio

Table 4 Multivariate analysis to identify the independent factors associated with the outcome in 192 patients with stable decompensated cirrhosis

\begin{tabular}{lcccc}
\hline Variable & $\begin{array}{c}\text { Odds } \\
\text { ratio }\end{array}$ & P value & \multicolumn{2}{c}{$95 \%$ Confidence interval } \\
\cline { 3 - 5 } & & & Lower & Upper \\
\hline $\begin{array}{l}\text { "True" } \\
\text { GFR }\end{array}$ & 0.96 & 0.035 & 0.92 & 0.99 \\
$\begin{array}{l}\text { Serum } \\
\text { ferritin }\end{array}$ & 1.001 & 0.005 & 1.00 & 1.002 \\
\hline
\end{tabular}

GFR, glomerular filtration rate

\section{Discussion}

In our study we evaluated for the first time in the same cohort the significance of serum ferritin and RDW/MPV in the outcome of patients with stable decompensated cirrhosis. The latter stands a clinical condition with very poor prognosis [2] and effort has been made to understand predictors of death risk. In clinical practice, several scores and markers are used to predict the patients' outcome [24]. Serum ferritin could be such a prognostic marker in patients with liver diseases, since it is widely available and its concentrations are correlated with the hepatic histological lesions in patients with non-hemochromatosis liver diseases, such as non-alcoholic fatty liver disease, alcoholic and viralrelated liver diseases [7,25].

The prognostic impact of ferritin has been evaluated not only in different causes, but also in different stages of severity of liver disease. Previous studies have demonstrated the importance of ferritin in acute on chronic liver failure [26,27], while recent studies have shown the association between ferritin and mortality in patients with decompensated cirrhosis. Hence, Walker et al [12] evaluated 191 candidates for LT and they found that baseline serum ferritin $>200 \mu \mathrm{g} / \mathrm{L}$ was an independent factor of mortality at 6 and 12 months. Interestingly, all deceased patients had serum ferritin greater than $400 \mu \mathrm{g} / \mathrm{L}$. However, in this study [12] although all patients had stable decompensated cirrhosis at baseline 
Table 5 Prediction of outcome using serum ferritin in 192 consecutive patients with stable decompensated cirrhosis

\begin{tabular}{|c|c|c|c|c|c|}
\hline Serum ferritin & Cut-off point (ng/mL) & Sensitivity (\%) & Specificity (\%) & PPV & NPV \\
\hline & 55 & 85.3 & 44.2 & 78 & 79 \\
\hline
\end{tabular}

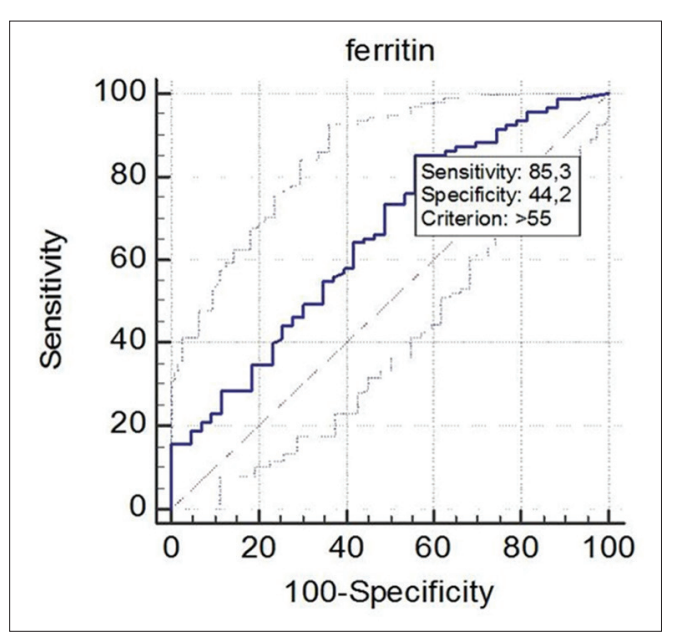

Figure 1 Area under the receiver operating characteristic curves (AUC) showing that ferritin had relatively low discriminative ability to the outcome (death or liver transplantation) (AUC $=0.61,95 \% \mathrm{CI}$ 0.52-0.69) in 192 patients with stable decompensated cirrhosis. The best cut-off point for the outcome was ferritin $>55 \mathrm{ng} / \mathrm{mL}$ yielding a sensitivity and specificity of $85.3 \%$ and $44.2 \%$, respectively

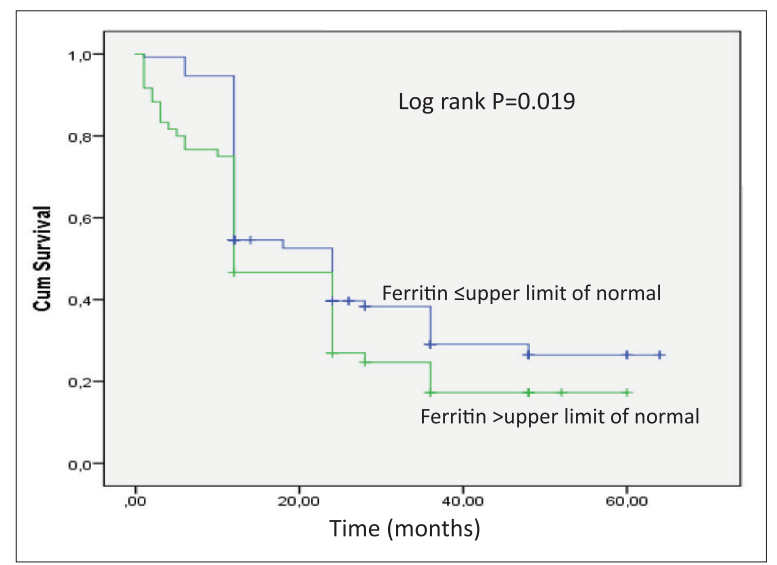

Figure 2 Survival of the patients with decompensated cirrhosis in association with serum ferritin; patients with ferritin levels above the upper limit of normal had worse outcome compared to those with low or normal ferritin levels $(\log \operatorname{rank} \mathrm{P}=0.019)$

without acute complications of cirrhosis during the previous month, no effort had been made to exclude the presence of infection. More recently, the correlation between serum ferritin levels with severity of hepatic decompensation was studied in 318 hospitalized decompensated cirrhosis patients by Maiwall et al [13]. The authors evaluated only the short term outcome (follow up for one month) and they included patients with or without acute complications of cirrhosis. The authors suggested ferritin to be a significant biomarker, which can predict early liver related death, and their results were confirmed in more recent studies $[27,28]$. In our study, we included 192 patients with decompensated cirrhosis to evaluate the prognostic impact of serum ferritin. Only patients with stable decompensated cirrhosis were evaluated, i.e. those without complications of cirrhosis during the last month and without any evidence of infection or other acute complication of cirrhosis at baseline. We confirmed previous findings [12,13], since ferritin was an independent factor of death or LT (in both genders) after a median follow-up period of 12 (range: 1-64) months. However, in our study, similar to previous studies $[12,13,29]$, the discriminative ability of ferritin was relatively low. In addition, in our study we found that "true" GFR was also an independent factor of death or LT. In the study by Walker et al [12] (in which patients with stable decompensated cirrhosis were included), serum sodium concentration was also associated with mortality in multivariate analysis, but it should be mentioned that neither "true" GFR nor estimated GFRs had been included in their analysis as prognostic factors.

The prognostic impact of ferritin in patients with decompensated cirrhosis might be expected, since patients with, compared to those without, ferritin above the upper limit of normal had significantly lower levels of albumin, higher levels of serum creatinine, bilirubin and INR, and as a result, significantly worse MELD and CTP scores. In addition, we found that the former group of patients had more frequently a previous history of SBP and encephalopathy. On the other hand, these patients showed less frequently variceal bleeding, an interesting finding that requires further elucidation.

Serum ferritin could predict the prognosis of patients with decompensated cirrhosis, since it reflects immune-mediated and infectious stimuli $[5,29]$. Enhanced bacterial translocation through the intestine contributes to endotoxinemia and systemic inflammation $[5,11,29]$. Although in our cohort we included only clinically stable patients without any evidence of overt bacterial inflammation (all patients had normal or slightly abnormal CRP), subclinical infection derived from translocation of bacterial products could not be excluded. Moreover, ferritin could express the severity of liver disease and possible subsequent complications [7,25,30]. Finally, it might reflect an iron overload condition resulting in significant morbidity and early mortality [6,31].

Apart from serum ferritin, we investigated in the same study the role of RDW and MPV in the outcome of our decompensated cirrhosis patients. These two parameters are commonly measured in blood tests. RDW is a measure of the variability of red blood cell size [32], while MPV reflects the platelet activation and function [33]. Huang et al found elevated RDW values in patients with HBV-related cirrhosis, without showing association with patients' prognosis [15]. Moreover, Giannini et al showed that in patients with 
cirrhosis, MPV had no association with severity of disease and prognosis [16], while other studies found high levels of RDW and MPV in advanced hepatic fibrosis and showed a positive correlation between their values and fibrosis in patients with chronic viral hepatitis [34-36]. These uncertain data led us to investigate the role of these markers, even in patients with diverse etiology of decompensated cirrhosis. In our cohort, we showed that there is no association between RDW and MPV and patients' outcome [HR 1.02, 95\%CI 0.96-1.09, $\mathrm{P}=0.53$ and HR $0.95,95 \%$ CI $0.84-1.08, \mathrm{P}=0.41$ ], irrespectively of the cause of the underlying disease.

We acknowledge that there are some limitations, including that it is a single-center study, while no other markers, such as hepcidin or transferrin saturation, were evaluated. However, for the first time in the same cohort, the role of serum ferritin and RDW/MPV in the outcome of patients with established stable decompensated cirrhosis were evaluated. Assessment of serum ferritin is easy for routine use and could provide additional important information to determine a strategy for our patients by predicting their outcome. In conclusion, our study confirmed previous findings that serum ferritin, but not RDW/MPV, was associated with the outcome of patients with established stable decompensated cirrhosis.

\section{Summary Box}

\section{What is already known:}

- Serum ferritin is associated with liver histological lesions in patients with chronic liver diseases

- Serum ferritin is an independent predictor of 12-month mortality in cirrhotic patients awaiting liver transplantation and early liver-related death in hospitalized patients with decompensated cirrhosis

- Red cell distribution width (RDW) and mean platelet volume (MPV) are independent predicting factors of hepatic fibrosis

\section{What the new findings are:}

- Serum ferritin is an independent factor of longterm outcome (death or liver transplantation) in patients with well-established stable decompensated cirrhosis

- There is no correlation between RDW / MPV and decompensated cirrhosis patients' outcome

\section{References}

1. Tsochatzis E, Bosch J, Burroughs AK. Liver cirrhosis. Lancet 2014;383:1749-1761.

2. Gines P, Quintero E, Arroyo V, et al. Compensated cirrhosis: natural history and prognostic factors. Hepatology 1987;7:122-128.
3. D’Amico G, Garcia-Tsao G, Pagliaro L. Natural history and prognostic indicators of survival in cirrhosis: A systematic review of 118 studies. J Hepatol 2006;44:217-231.

4. Prieto J, Barry M, Sherlock S. Serum ferritin in patients with iron overload and with acute and chronic liver diseases. Gastroenterology 1975;68:525-533.

5. Harrison PM, Arosio P. The ferritins: molecular properties, iron storage function and cellular regulation. Biochim Biophys Acta 1996;1275:161-203.

6. Knovich MA, Storey JA, Coffman LG, Torti SV, Torti FM. Ferritin for the clinician. Blood Rev 2009;23:95-104.

7. Hearnshaw S, Thompson NP, McGill A. The epidemiology of hyperferritinaemia. World J Gastroenterol 2006;12:5866-5869.

8. Kuhn LC. How iron controls iron. Cell Metabolism 2009;10:439-441.

9. Nemeth E, Tuttle MS, Powelson J, et al. Hepcidin regulates cellular iron efflux by binding to ferroportin and inducing its internalization. Science 2004;306:2090-2093.

10. Detivaud L, Nemeth E, Boudjema K, et al. Hepcidin levels in humans are correlated with hepatic iron stores, hemoglobin levels, and hepatic function. Blood 2005; 106:746-748.

11. Ryan JD, Chin JL, Crowe J. Ferritin in decompensated cirrhosis: iron or inflammation? J Hepatol 2015;62:499-500.

12. Walker NM, Stuart KA, Ryan RJ, et al. Serum ferritin concentration predicts mortality in patients awaiting liver transplantation. Hepatology 2010;51:1683-1691.

13. Maiwall R, Kumar S, Chaudhary AK, et al. Serum ferritin predicts early mortality in patients with decompensated cirrhosis. J Hepatol 2014;61:43-50.

14. Karagoz E, Ulcay A, Tanoglu A, et al. Clinical usefulness of mean platelet volume and red blood cell distribution width to platelet ratio for predicting the severity of hepatic fibrosis in chronic hepatitis B virus patients. Eur J Gastroenterol Hepatol 2014;26:1320-1324.

15. Huang R, Yang C, Wu K, et al. Red cell distribution width as a potential index to assess the severity of hepatitis B virus-related liver diseases. Hepatol Res 2014;44:464-470.

16. Giannini EG, Moscatelli A, Brunacci M, Zentilin P, Savarino V. Prognostic role of mean platelet volume in patients with cirrhosis. Digest Liver Dis 2016;48:409-413.

17. Pugh RN, Murray-Lyon IM, Dawson JL, Pietroni MC, Williams R. Transection of the oesophagus for bleeding oesophageal varices. $\mathrm{Br}$ J Surg 1973;60:646-649.

18. Kamath SP, Wiesner HR, Malinchoc M, et al. A model to predict survival in patients with end-stage liver disease. Hepatology 2001;33:464-470.

19. Cholongitas E, Goulis J, Arsos G, et al. Association between ratio of sodium to potassium in random urine samples and renal dysfunction and mortality in patients with decompensated cirrhosis. Clin Gastroenterol Hepatol 2013;11:862-867.

20. Fleming JS, Nunan TO. The new BNMS guidelines for measurement of glomerular filtration rate. Nucl Med Commun 2004;25:755-757.

21. Levey AS, Bosch JP, Lewis JB, Greene T, Rogers N, Roth D. A more accurate method to estimate glomerular filtration rate from serum creatinine: a new prediction equation. Modification of Diet in Renal Disease Study Group. Ann Intern Med 1999;130:461-470.

22. Levey AS, Stevens LA, Schmid CH, et al. A new equation to estimate glomerular filtration rate. Ann Intern Med 2009;150:604-612.

23. Hanley JA, McNeil BJ. A method of comparing the areas under receiver operating characteristic curves derived from the same cases. Radiology 1983;148:839-843.

24. D’Amico G, Morabito A, Pagliaro L, Marubini E. Survival and prognostic indicators in compensated and decompensated cirrhosis. Dig Dis Sci 1986;31:468-475.

25. Manousou P, Kalambokis G, Grillo F, et al. Serum ferritin is a discriminant marker for both fibrosis and inflammation in histologically proven non-alcoholic fatty liver disease patients. 
Liver Int 2011;31:730-739.

26. $\mathrm{Wu}$ J, Chen $\mathrm{L}$, Chen Y, et al. Serum ferritin concentration predicts mortality in patients with hepatitis B virus-related acute on chronic liver failure. Arch Med Res 2014;45:251-256.

27. Maras JS, Maiwall R, Harsha HC, et al. Dysregulated iron homeostasis is strongly associated with multiorgan failure and early mortality in acute-on-chronic liver failure. Hepatology 2015;61:1306-1320.

28. Bruns T, Nuraldeen R, Mai M, et al. Low serum transferrin correlates with acute-on-chronic organ failure and indicates short-term mortality in decompensated cirrhosis. Liver Int 2016; (in press).

29. Weismüller TJ, Kirchner GI, Scherer MN, et al. Serum ferritin concentration and transferrin saturation before liver transplantation predict decreased long-term recipient survival. Hepatology 2011;54:2114-2124.

30. Waidmann O, Brunner F, Herrmann E, Zeuzem S, Piiper A, Kronenberger B. Macrophage activation is a prognostic parameter for variceal bleeding and overall survival in patients with liver cirrhosis. J Hepatol 2013;58:956-961.

31. Lieu PT, Heiskala M, Peterson PA, Yang Y. The roles of iron in health and disease. Mol Aspects Med 2001;22:1-87.

32. Evans TC, Jehle D. The red blood cell distribution width. J Emerg Med 1991;9:71-74.

33. Colkesen Y, Muderrisoglu H. The role of mean platelet volume in predicting thrombotic events. Clin Chem Lab Med 2012;50:631-634.

34. Taefi A, Huang CC, Kolli K, Ebrahimi S, Patel M. Red cell distribution width to platelet ratio, a useful indicator of liver fibrosis in chronic hepatitis patients. Hepatol Int 2015;9:454-460.

35. Ekiz F, Yuksel O, Kocak E, et al. Mean platelet volume as a fibrosis marker in patients with chronic hepatitis B. J Clin Lab Anal 2011;25:162-165.

36. Purnak T, Olmez S, Torun S, et al. Mean platelet volume is increased in chronic hepatitis $\mathrm{C}$ patients with advanced fibrosis. Clin Res Hepatol Gas 2013;37:41-46. 